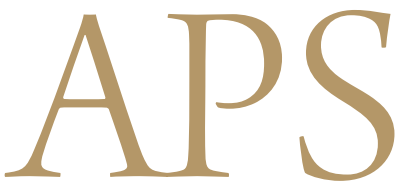

Archives of Plastic Surgery

\title{
Effectiveness of mini-open carpal tunnel release: An outcome study
}

\author{
Lieselotte R. van den Broeke ${ }^{1}$, Willem. J. Theuvenet ${ }^{1}$, Jan. J. van Wingerden ${ }^{1,2}$ \\ ${ }^{1}$ Department of Plastic, Reconstructive and Hand Surgery, Gelre Hospital, Apeldoorn; ${ }^{2}$ Department of Plastic, Reconstructive and Hand \\ Surgery, Academic Medical Center, University of Amsterdam, Amsterdam, the Netherlands
}

Background Carpal tunnel syndrome (CTS) is the most common peripheral entrapment neuropathy with a high morbidity and healthcare-related costs. Currently there is no consensus about the best treatment option. The purpose of this prospective cohort study conducted at a single institution was to evaluate the clinical outcomes and patient satisfaction following a mini-open carpal tunnel release for idiopathic CTS.

Methods A total of 72 patients (53 female and 19 male patients; mean age, $57.8 \pm 15.3$ years; range, 24-94 years) had a mini-open carpal tunnel release performed by a single senior surgeon between June 2015 and June 2016. The patients were evaluated preoperatively, and at 3 and 12 months post-intervention. At every follow-up, the Boston Carpal Tunnel Syndrome Questionnaire (BCTSO) and visual analogue scale (VAS) scores for pain and satisfaction were completed. Digital sensibility (using Semmes- Weinstein monofilaments) was assessed and pinch and grip strengths were measured.

Results Statistically significant and clinically relevant improvement was found in terms of digital sensibility, grip and pinch strength (except for 2-point pinch), BCTSO scores and pain scores. The complication rate was minimal, and no major complications occurred. Two patients experienced recurrence. The availability of follow-up records (including patient-reported outcomes, BCTSO and VAS scores, and the complication rate) at 1-year post-intervention varied between $69 \%$ and $74 \%$ (50-53 patients) depending on which parameter was assessed. Patient satisfaction was high (mean, $80.9 \pm 26.0$; range, $0-100$ ).

Conclusions This study demonstrates that mini-incision carpal tunnel release is clinically effective in the short and long term.

Keywords Carpal tunnel syndrome / Patient reported outcome measures / Treatment outcome / Decompression, surgical

\author{
Correspondence: \\ Lieselotte R. van den Broeke \\ Department of Plastic, Reconstructive \\ and Hand Surgery, Gelre Hospital, \\ Albert Schweitzerlaan 31, Apeldoorn \\ $7334 \mathrm{DZ}$, the Netherlands \\ Tel: +31-612-786-833 \\ Fax: +31-55-581-1249 \\ E-mail: lieselottevandenbroeke@ \\ hotmail.com
}

The authors gratefully acknowledge the assistance of Hanna van Eijsden, physiotherapist (data collection) and Dr. Hester van der Zaag-Loonen, epidemiologist (data analysis).

Received: 26 May 2018 • Revised: 23 Dec $2018 \bullet$ Accepted: 1 Feb 2019

pISSN: 2234-6163 • elSSN: 2234-6171 • https://doi.org/10.5999/aps.2018.00535• Arch Plast Surg 2019;46:350-358

\section{INTRODUCTION}

Carpal tunnel syndrome (CTS) is the most common peripheral nerve entrapment syndrome worldwide [1]. Its incidence peaks in the age group of 40 to 60 years, and it is three times more common in women than in men [2]. Various non-surgical and surgical treatment options exist for CTS. Currently, surgical treatment is indicated when symptoms are severe or when conservative treatment has failed [3]. The basic principle of CTS surgery is to increase the volume of the carpal tunnel, thereby 
releasing pressure on the median nerve [4]. Approaches for carpal tunnel release (CTR) have been extensively investigated, and several distinct techniques and instruments have been introduced to increase the success rate of carpal tunnel surgery. The traditional surgical approach is a standard open CTR. Modified open CTR involves an incision of a similar length (approximately $5 \mathrm{~cm}$ ), but specific care is taken to preserve the superficial nerve branch crossing the incision site. In the miniopen CTR, the transverse carpal ligament is divided through a significantly smaller incision $(1-3 \mathrm{~cm})$. The transverse carpal ligament can also be divided with the use of an endoscopic camera, optical fiber light source, monitor and 1 or 2 portals $[5,6]$.

The high prevalence of CTS, its effect on quality of life, and the resultant healthcare costs make it essential to identify the most cost-efficient and patient-friendly treatment method. This study aimed to generate insights into short- and long-term clinical outcomes and patient satisfaction after mini-open CTR.

The aim of this study was to evaluate the clinical and patientreported outcomes of mini-open incision CTR in the short and long term, and to serve as a basis for future outcome studies of mini-open CTR. For the purpose of this study, "short-term" was defined as 3 months post-intervention and long term as 1-year post-intervention.

\section{METHODS}

\section{Study design}

This was a single-group prospective cohort study designed to determine the clinical outcomes and patient-reported satisfaction following a mini-open CTR in the short and long term. The institutional Review Board (IRB) approved the study (RF TCO nr.16.29). Informed consent was obtained from all patients for the operation and the preoperative and postoperative assessments. Demographic and preoperative clinical data were collected preoperatively (T0). All patients $(\mathrm{n}=72)$ had received a mini-open CTR done under local anesthesia. Clinical and patient-reported outcomes were evaluated on an outpatient basis at 3 months (T1) and 1 year (T2) post-intervention. Motor and sensory tests were performed on a randomly selected group $(\mathrm{n}=52)$ of patients. Postoperative complications were recorded. Each patient $(\mathrm{n}=72)$ was sent the Boston Carpal Tunnel Syndrome Questionnaire (BCTSQ) by post to gain insight into the degree of recovery and patient satisfaction. Unsatisfied patients and patients with incongruent answers were contacted by telephone to avoid misinterpretation or miscommunication. Patients lost to follow-up were contacted when possible to verify their reasons for stopping participation.

\section{Participants}

The inclusion of participants is summarized in the flowchart presented in Fig. 1. A total of 72 patients were included between June 2015 and June 2016 at the Outpatient Clinic of the Department of Plastic, Reconstructive and Hand Surgery of Gelre Hospital. Only patients with idiopathic CTS (not caused by an acute trauma or any systemic disease) who had not previously undergone carpal tunnel surgery and who were considered suitable for a mini-open incision under local anesthesia were included. The diagnosis of CTS was required to comply with the guidelines of the Dutch Society of Neurology [3] and was only made following a complete anamnesis, a thorough physical examination and nerve conduction studies (NCSs). The exclusion criteria were post-surgical recurrence of CTS, inflammatory arthropathy, deformities of the affected hand/wrist, candidates for CTR under general anesthesia (because of co-morbidities or anxiety), neuropathies or myopathies or an age of less than 18 years.

\section{Intervention}

All patients underwent CTR through a mini-open incision, performed by a single senior surgeon (WJT) in an outpatient setting under local anesthesia with the aid of a tourniquet inflated to 100 $\mathrm{mmHg}$ above systolic blood pressure. The upper limb was placed on an arm board in an abducted position. The forearm was supinated and the wrist was kept in slight extension. A longitudinal incision of $1-2 \mathrm{~cm}$ was made distal to the transverse skin fold in the extension of the palmaris longus tendon. The incision was located closer to the ulnar side of the median nerve to decrease the risk of injury to the palmar cutaneous and recurrent motor branches (Fig. 2). Following the skin incision, the palmaris longus tendon, where present, was held aside radially. In this way the roof of the carpal tunnel was exposed while the more superficial subcutaneous tissue, which was retracted bilaterally, was preserved. A plane superficial to the transverse carpal ligament was created by spreading the Stephens scissors. The transverse carpal ligament was cut under direct vision. Complete release was ensured and a depot of $0.5 \%$ bupivacaine was instilled prior to skin closure with $5 / 0$ absorbable (either polyglactin 910 or polyglycolic acid) interrupted sutures. A light pressure dressing was applied for a week and patients were discharged directly post-intervention. Movement of the fingers was started immediately postoperatively and encouraged as much as the light compression dressing allowed.

\section{Measurements}

Preoperative NCSs were done in accordance with the current guidelines of the Dutch Society of Neurologists [2], measuring 


\section{Fig. 1. Flowchart of included participants}

A total of 174 patients were assessed for eligibility between June 2015 and June 2016 at the outpatient clinic of the department of plastic, reconstructive and hand surgery. Only patients with idiopathic carpal tunnel syndrome (CTS) with no history of carpal tunnel surgery who were suitable for mini-open incision under local anesthesia were included $(n=72)$. Patients with a post-surgical recurrence, deformities of the hand/ wrist, carpal tunnel release (CTR) under general anesthesia, no informed consent, arthropathies, neuropathies or myopathies, or age under 18 years were excluded $(n=102)$. A total of 19-22 patients did not attend follow-up visits depending on which parameter was assessed, resulting in 50 to 53 participants with complete data available for analysis at 1-year post-intervention.

Enrolment at outpatient plastic surgery clinic

Motor and sensory tests were only
performed in a randomly selected group
\[ (n=52) \]

Assessed for eligibility $(n=174)$

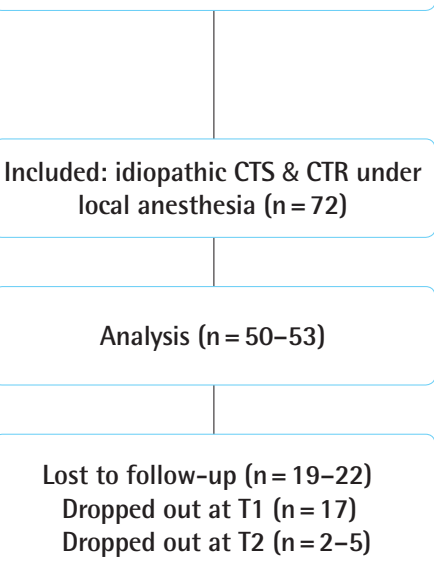

Excluded $(n=102)$

1. Post-surgical recurrence

2. Deformities of the hand/wrist

3. Candidates for CTR under general anaesthesia

4. No informed consent

5. Arthropathies, neuro- or myopathies

6. Age under 18 years

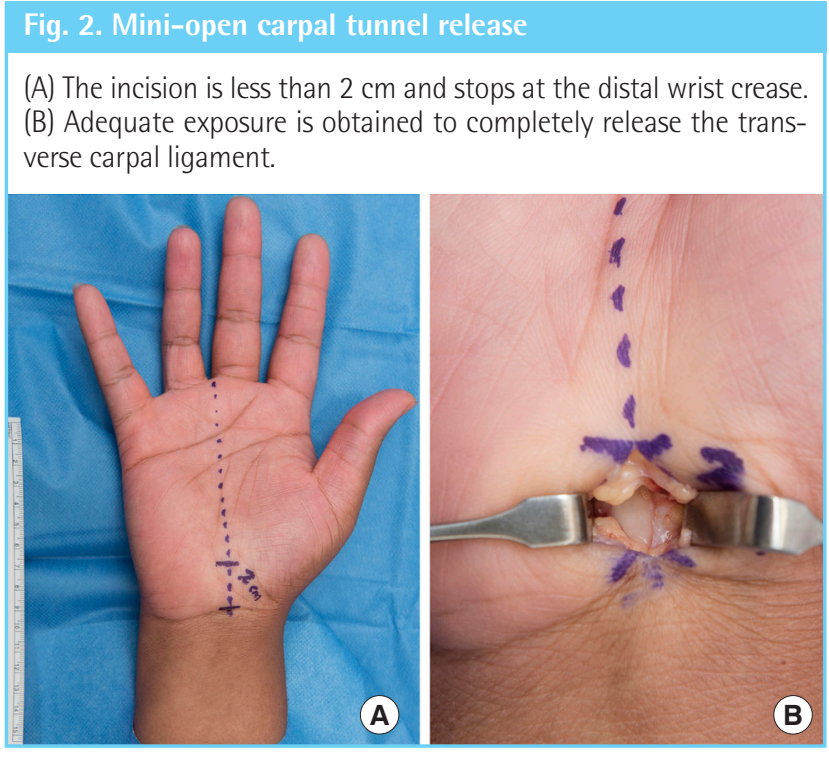

the distal motor and sensory latency, amplitude, and conduction velocity of the median nerves across the carpal tunnel and all along its course. Multiple compression neuropathies were
Table 1. The AAEM classification for determining the degree of CTS

\begin{tabular}{|c|c|}
\hline The AAEM classification & Criteria \\
\hline 1. Mild CTS & $\begin{array}{l}\text { Only sensory peak latency and falling sensory } \\
\text { amplitude }\end{array}$ \\
\hline 2. Moderate CTS & $\begin{array}{l}\text { Abnormal median sensory interaction with } \\
\text { addition of motor distal latency prolongation }\end{array}$ \\
\hline 3. Severe CTS & $\begin{array}{l}\text { Median motor and sensory distal latency } \\
\text { prolongation in addition to sensory and motor } \\
\text { amplitude decrease }\end{array}$ \\
\hline 4. Very severe CTS & No median sensory or motor responses \\
\hline
\end{tabular}

ruled out. The results were classified according to the American Association of Electrodiagnostic Medicine criteria (Table 1), for the severity of median nerve lesions [4].

Preoperatively and postoperatively, motor and sensory function tests were done by a qualified hand therapist. The motor tests included measurements of hand grip and pinch strength (key, 2-point and 3-point). These tests were performed accord- 
ing to standard procedures ( 3 recordings per measure, the best result being registered) using a dynamometer and a pinch meter (E-Link, Biometrics Ltd., Newport, UK). Digital sensibility of the thumb, index, and middle fingers was measured using Semmes-Weinstein monofilaments (Touch-Test Sensory Evaluator, Morgan Hill, CA, USA).

Patient-reported outcomes were evaluated using a questionnaire. Patients reported a visual analogue scale (VAS) score for pain at rest and during activity. The VAS was a horizontal $100-\mathrm{mm}$ line with a scale from 0 to 100 ( 0 equaling no pain and 100 corresponding to the most intense pain). Patients were asked to grade their pain by drawing a stripe along this line. Satisfaction with surgery at follow-up at 3 (T1) and 12 months (T2) was evaluated in the same manner. The severity of symptoms was quantified using the $B C T S Q_{2}$ a validated, patient-orientated, and highly reproducible questionnaire [7]. The BCTSQ evaluates symptoms with 11 parameters and function with eight parameters. Each parameter is scored on a 5-point scale, with higher scores indicating more severe symptoms and lower function. When complications (hematoma, necrosis, complex regional pain syndrome type 1 [CRPS type 1], delayed wound healing, infection, arterial or nerve damage) occurred, they were registered.

\section{Statistical analysis}

Statistical analyses were performed using SPSS version 17.0 (SPSS Inc., Chicago, IL, USA). The evaluation of the data included descriptive statistical methods (mean, standard deviation, ranges, absolute numbers, and percentages) and statistical comparisons. The paired t-test was used to analyze preoperative and postoperative assessments if the data were normally distributed and continuous (grip and pinch strength), and the Wilcoxon signed-rank test was used for non-normally distributed continuous or ordinal data (sensibility, overall BCTSQ score). The Mann-Whitney $U$ test was used to analyze the relationships of the BCTSQ score with the duration of symptoms and NCS abnormalities. The chi-square test was used to analyze the relationship between postoperative paraesthesia and age. The duration of symptoms, NCS abnormalities, and age were dichotomized to create sufficient power for analysis. Analyses were performed at the group level and represented by P-values. A twotailed P-value $<0.05$ was considered to indicate statistical significance. The data were analyzed using completed datasets.

\section{RESULTS}

\section{Baseline and follow-up}

Demographic and baseline clinical data for the patient cohort are shown in Table 2. In total, 72 patients were included (time 0 ,

\section{Table 2. Patient characteristics}

\begin{tabular}{lc|}
\hline Parameter & $\begin{array}{c}\text { Baseline characteristics T0 } \\
(\mathrm{n}=72)\end{array}$ \\
\hline Age (yr) & $57.8 \pm 15.3(24-94)$ \\
Sex & $19(26)$ \\
Male & $53(74)$ \\
Female & \\
Employment status & $39(54)$ \\
Yes & $33(46)$ \\
No & \\
Hand dominance & $63(88)$ \\
Right & $8(11)$ \\
Left & $1(1)$ \\
Unknown & \\
Operated hand & $40(56)$ \\
Right & $32(44)$ \\
Left & \\
Duration of symptoms (mon) & $23(32)$ \\
1-6 & $9(13)$ \\
6-12 & $40(56)$ \\
$>12$ & \\
AAEM degree of CTS a) & $1(1)$ \\
Normal & $7(10)$ \\
Mild & $37(51)$ \\
Moderate & $23(32)$ \\
Severe & $2(3)$ \\
Extremely severe & $2(3)$ \\
Unknown & \\
\hline Values are presented as mean \pm SD (range) or number $(\%)$. \\
AAEM, American Association of Electrodiagnostic Medicine; CTS, carpal tunnel \\
syndrome. \\
a)See Table 1. \\
\hline
\end{tabular}

T0). All patients underwent mini-open CTR. Follow-up examinations were performed at 3 months post-intervention (time 1, $\mathrm{T} 1)$ and at 1-year post-intervention (time 2, T2).

\section{Clinical outcomes}

Table 3 presents patients' grip and pinch strengths at 3 months (T1) and 1 year (T2) post-intervention compared with the preoperative measurements ( $\mathrm{T} 0$ ). Relative to the preoperative measurements, statistically significant mean improvements in total grip strength $(\mathrm{P}<0.05)$, 3-point pinch strength $(\mathrm{P}=0.002)$, and key pinch strength $(\mathrm{P}<0.007)$ were found at 1 -year post-intervention. Two-point pinch strength did not significantly improve $(\mathrm{P}=0.232)$.

The sensibility of the first 3 digits (thumb, index finger, and middle finger) improved significantly when the preoperative measurements were compared to those made at 1-year post-intervention $(P=0.011)$ (Table 4$)$. Sensibility improved on average from a target bending force of $5.24 \pm 21.1 \mathrm{~g}$ (range, 0.07 $102.67 \mathrm{~g}$ ) at baseline to $0.49 \pm 0.7 \mathrm{~g}$ (range, $0.07-3.33 \mathrm{~g}$ ) at 1 -year post-intervention. At baseline, six patients $(13 \%)$ had loss of protective sensation in digit I, five patients (11\%) had loss of 
Table 3. Grip and pinch strength preoperatively, 3 months and 1-year post-intervention

\begin{tabular}{|c|c|c|c|c|}
\hline Strength (kg) & Preoperative (T0) $(n=52)$ & At 3 months $(T 1)(n=32)$ & At 12 months (T2) $(n=33)$ & P-value ${ }^{a)}$ \\
\hline Grip & $22.4 \pm 10.9(4.0-51.5)$ & $22.4 \pm 8.5(11-48)$ & $24.9 \pm 10.9(4-57)$ & 0.05 \\
\hline Key pinch & $5.8 \pm 2.2(1.3-10.3)$ & $5.5 \pm 6.3(7-30)$ & $6.6 \pm 2.4(1-11)$ & 0.007 \\
\hline 3-point pinch & $5.1 \pm 2.3(0.8-10.1)$ & $5.3 \pm 2.0(2-10)$ & $6.2 \pm 2.6(2-14)$ & 0.002 \\
\hline 2-point pinch & $4.1 \pm 1.9(0.8-8.9)$ & $4.3 \pm 1.8(2-9)$ & $4.5 \pm 1.8(1-9)$ & 0.232 \\
\hline
\end{tabular}

Table 4. Digital sensibility (target forces in grams) preoperatively versus at 1-year post-intervention

\begin{tabular}{|c|c|c|c|}
\hline Sensibility target force (g) & Preoperative (T0) $(n=52)$ & At 1 year $(T 2)(n=35)$ & P-value ${ }^{\text {a) }}$ \\
\hline Digit I & $14.22 \pm 62.3(0-300)$ & $0.60 \pm 0.8(0.07-4)$ & 0.037 \\
\hline Digit II & $0.84 \pm 1.1(0.07-4)$ & $0.47 \pm 0.8(0.07-4)$ & 0.023 \\
\hline Digit III & $0.67 \pm 0.9(0.07-4)$ & $0.39 \pm 0.6(0.07-2)$ & 0.005 \\
\hline Average of digits I, II, III & $5.24 \pm 21.1(0.07-102.67)$ & $0.49 \pm 0.7(0.07-3)$ & 0.011 \\
\hline
\end{tabular}

\begin{tabular}{|c|c|c|}
\hline $\begin{array}{l}\text { Sensory test (Semmes- } \\
\text { Weinstein monofilaments) }\end{array}$ & $\begin{array}{l}\text { Preoperative (T0) } \\
\qquad(\mathrm{n}=46)\end{array}$ & $\begin{array}{l}\text { At } 1 \text { year }(T 2) \\
(n=35)\end{array}$ \\
\hline \multicolumn{3}{|l|}{ Digit I } \\
\hline 6.65 & $3(6.5)$ & 0 \\
\hline 4.56 & $3(6.5)$ & $1(2.9)$ \\
\hline 4.31 & $10(21.7)$ & $4(11.4)$ \\
\hline 3.61 & $18(39.1)$ & $21(60.0)$ \\
\hline 2.83 & $12(26.1)$ & $9(25.7)$ \\
\hline \multicolumn{3}{|l|}{ Digit II } \\
\hline 6.56 & $1(2.2)$ & 0 \\
\hline 4.56 & $4(8.7)$ & $1(2.9)$ \\
\hline 4.31 & $6(13.0)$ & $2(5.7)$ \\
\hline 3.61 & $22(47.8)$ & $19(54.3)$ \\
\hline 2.83 & 13 (28.3) & $13(37.1)$ \\
\hline \multicolumn{3}{|l|}{ Digit III } \\
\hline 6.56 & $1(2.2)$ & 0 \\
\hline 4.56 & $2(4.3)$ & 0 \\
\hline 4.31 & $6(13.0)$ & $4(11.4)$ \\
\hline 3.61 & $23(50.0)$ & $11(31.4)$ \\
\hline 2.83 & 14 (30.4) & $20(57.1)$ \\
\hline
\end{tabular}

Values are presented as number (\%). Semmes-Weinstein monofilaments: $2.83=$ normal sensibility, $3.61=$ diminished light touch, $4.31=$ diminished protective sensation, $4.56=$ loss of protective sensation, $6.65=$ deep pressure sensation only.

protective sensation in digit II and three patients (7\%) had loss of protective sensation in digit III. At 1-year post-intervention, only two patients continued to have loss of protective sensation ( 1 patient in digit I and 1 patient in digit II) (Table 5).

Two patients (3.8\%) required re-exploration for inadequate symptom relief and improvement within the year of follow-up. None of the other patients suffered any major complications,

\begin{tabular}{ll} 
Table 6. Complications over a period of 1 year $(n=53)$ \\
\hline & No. $(\%)$ \\
\hline No complications & $47(89)$ \\
Complications & \\
Hematoma & 0 \\
CRPS type 1 & 0 \\
Neurovascular & 0 \\
Pillar pain & $3(5.7)$ \\
Re-exploration & $2(3.8)$ \\
Infection & $1(1.9)$ \\
Total & $6(11)$ \\
\hline CRPS type 1, complex regional pain syndrome type 1. &
\end{tabular}

such as injury to the median nerve or its branches, CRPS type 1, hematoma, or deep infection. A superficial infection was observed in one patient, and was successfully treated with antibiotic therapy. Pillar pain was the most common complaint (5.7\%, $\mathrm{n}=3$ ) (Table 6).

\section{Patient-reported outcomes}

Complete patient-reported outcome data were available from 51 patients at 1 year after surgery (T2), as one patient did not complete the VAS pain score. Table 7 shows the number and percentage of complaints preoperatively and postoperatively. Preoperatively, the majority of the patients reported night pain $(97.2 \%, \mathrm{n}=70)$, numbness $(93.1 \%, \mathrm{n}=67)$, and paraesthesia (97.2\%, $n=70)$. At the 3-month follow-up, 69.8\% ( $n=37)$ of the patients had no night pain, $58.5 \%(\mathrm{n}=31)$ no numbness and $64.2 \%(\mathrm{n}=34)$ no paraesthesia. At 1-year post-intervention, $84.3 \%$ of patients $(n=43)$ had no night pain, $68.6 \%(n=35)$ no 
numbness, and $76.5 \%(\mathrm{n}=39)$ no paraesthesia. Preoperatively, half of the patients $(\mathrm{n}=36)$ had had severe to very severe night pain, $26.4 \%(n=19)$ severe to very severe numbness and $40.3 \%$ $(n=29)$ severe to very severe paraesthesia. Extremely severe night pain and paraesthesia completely disappeared postoperatively. At 1-year post-intervention, a minority of patients report-

Table 7. Night pain, numbness, and paraesthesia preoperatively, 3 months and 1-year post-intervention

\begin{tabular}{|lccc|}
\hline Complaints & $\begin{array}{c}\text { Preoperative } \\
(\text { T0) } \\
(\mathbf{n}=\mathbf{7 2})\end{array}$ & $\begin{array}{c}\text { At } 3 \text { months } \\
(\mathbf{T} 1) \\
(\mathbf{n}=\mathbf{5 3})\end{array}$ & $\begin{array}{c}\text { At } 12 \text { months } \\
(\mathbf{T} 2) \\
(\mathbf{n}=\mathbf{5 1})\end{array}$ \\
\hline Night pain & & & \\
No & $2(2.8)$ & $37(69.8)$ & $43(84.3)$ \\
Mild & $11(15.3)$ & $11(20.8)$ & $4(7.8)$ \\
Moderate & $22(30.6)$ & $5(9.4)$ & $2(3.9)$ \\
Severe & $27(37.5)$ & 0 & $2(3.9)$ \\
Extremely severe & $9(12.5)$ & 0 & 0 \\
Numbness & & & \\
No & $5(6.9)$ & $31(58.5)$ & $35(68.6)$ \\
Mild & $14(19.4)$ & $14(26.4)$ & $12(23.5)$ \\
Moderate & $34(47.2)$ & $4(7.5)$ & $1(2.0)$ \\
Severe & $13(18.1)$ & $3(5.7)$ & $2(3.9)$ \\
Extremely severe & $6(8.3)$ & $1(1.9)$ & $1(2.0)$ \\
Paraesthesia & & & \\
$\quad$ No & $2(2.8)$ & $34(64.2)$ & $39(76.5)$ \\
Mild & $11(15.3)$ & $14(26.4)$ & $8(15.7)$ \\
Moderate & $29(40.3)$ & $3(5.7)$ & $2(3.9)$ \\
Severe & $25(34.7)$ & $2(3.8)$ & $2(3.9)$ \\
Extremely severe & $4(5.6)$ & 0 & 0 \\
\hline Values are presented as number (\%). & & \\
\hline
\end{tabular}

\section{Table 8. Post-intervention paraesthesia related to age}

\begin{tabular}{|c|c|c|c|c|}
\hline & \multicolumn{2}{|c|}{$\begin{array}{l}\text { At } 3 \text { months (T1) } \\
\text { paraesthesia } \\
(n=53)^{\text {a) }}\end{array}$} & \multicolumn{2}{|c|}{$\begin{array}{l}\text { At } 12 \text { months (T2) } \\
\text { paraesthesia } \\
(n=51)^{b)}\end{array}$} \\
\hline & Yes & No & Yes & No \\
\hline Age < 60 yr & 7 & 21 & 7 & 18 \\
\hline Age $>60$ yr & 12 & 13 & 6 & 20 \\
\hline
\end{tabular}

ed that they still had severe night pain $(3.9 \%, n=2)$, paraesthesia $(3.9 \%, \mathrm{n}=2)$ or severe to very severe numbness $(5.9 \%$, $n=3)$. No relationship was found between persistent postoperative paraesthesia and older age (above 60 years) (Table 8 ).

The mean overall BCTSQ scores were 49.6 \pm 11.8 (range, 2375 ) preoperatively (T0), $29.0 \pm 10.5$ (range, $18-56$ ) at 3 months (T1), and 26.7 \pm 9.8 (range, 18-57) at 1-year post-intervention. The BCTSQ scores showed a significant improvement $(\mathrm{P}<$ 0.0001 ), with a difference in the mean score of 22.9 points over 1 year (Table 9). No relationships were found between postoperative recovery, as represented by the BCTSQ score, and the preoperative degree of NCS abnormalities or duration of symptoms. Patients with mild to moderate pain, and those with severe to extremely severe NCS abnormalities, had nearly the same BCTSQ scores preoperatively and postoperatively, as did patients whose symptoms had lasted for more or less than 1 year (Table 10).

At baseline, for pain during activity, patients reported a mean VAS score of $46 \pm 29.1$ (range, 0-94), and for pain at rest, a mean VAS score of $38 \pm 31.5$ (range, $0-93$ ). At 3 months post-intervention, the scores were $24.7 \pm 16.4$ (range, 0-69) and $11.3 \pm$ 25.0 (range, $0-87$ ) respectively, and at 1-year post-intervention, they were $12.7 \pm 14.0$ (range, $0-78$ ) and $7.0 \pm 19.3$ (range, 0-67) respectively. Patient satisfaction was $78.4 \pm 23.4$ (range, $6-100)$ at the 3-month follow-up and $80.9 \pm 26.0(0-100)$ at the 1-year follow-up (Table 11).

\section{DISCUSSION}

This prospective, single-center study demonstrated the benefits of mini-open CTR under local (infiltrating) anesthesia, in terms of clinical recovery and relief of symptoms in the short and long term ( 3 and 12 months, respectively). These improvements were of both statistical significance and clinical relevance.

The strengths of this study were the prospective data collection, a wide range of predefined validated outcome measurements, comparisons between subjective and objective findings, short-term (3 months) and long-term (12 months) follow-up,

\section{Table 9. VAS and BCTSO scores preoperatively, 3 months and 1-year post-intervention}

\begin{tabular}{|c|c|c|c|c|}
\hline & Preoperative (T0) $(n=68)$ & At 3 months $(T 1)(n=53)$ & At 12 months $(T 2)(n=51)$ & P-value ${ }^{a)}$ \\
\hline BCTSQ score & $49.6 \pm 11.8(23-75)$ & $29.0 \pm 10.5(18-56)$ & $26.7 \pm 9.8(18-57)$ & $<0.0001$ \\
\hline \multicolumn{5}{|l|}{ VAS pain ${ }^{\text {b) }}$} \\
\hline During activity & $46.0 \pm 29.1(0-94)$ & $24.7 \pm 16.4(0-69)$ & $12.7 \pm 14.0(0-78)$ & \\
\hline At rest & $38.0 \pm 31.5(0-93)$ & $11.3 \pm 25.0(0-87)$ & $7.0 \pm 19.3(0-67)$ & \\
\hline
\end{tabular}

Values are presented as mean $\pm S D$ (range).

VAS, visual analogue scale (in the range of 0 to 100, $0=$ no pain and 100=maximum of pain); BCTSQ, Boston Carpal Tunnel Syndrome Questionnaire.

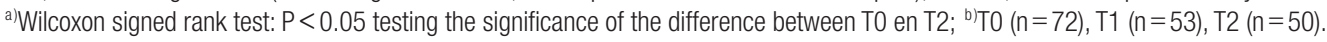


Table 10. Relationships of the duration of symptoms and preoperative NCS abnormalities with the improvement of BCTSO scores over a period of 1 year

\begin{tabular}{|c|c|c|c|}
\hline & \multicolumn{2}{|c|}{ BCTSO score } & \multirow{2}{*}{ P-value } \\
\hline & Preoperative (T0) $(n=68)$ & At 12 months $(T 2)(n=51)$ & \\
\hline \multicolumn{4}{|l|}{ Symptoms $^{\text {b) }}$} \\
\hline$<1 \mathrm{yr}$ & $51.4 \pm 13.9(23-75), n=32$ & $27.0 \pm 10.8(18-57), n=25$ & $<0.0001$ \\
\hline$>1 \mathrm{yr}$ & $48.8 \pm 10.5(26-71), n=40$ & $25.5 \pm 8.7$ (18-49), $n=26$ & $<0.0001$ \\
\hline \multicolumn{4}{|l|}{ NCS ${ }^{c)}$} \\
\hline Mild to moderate & $48.9 \pm 11.1(23-70), n=45$ & $26.6 \pm 9.4(18-49), n=32$ & $<0.0001$ \\
\hline NCS severe to very severe & $49.9 \pm 12.6(28-75), n=25$ & $27.0 \pm 10.8(18-57), n=19$ & $<0.0001$ \\
\hline
\end{tabular}

Values are presented as mean $\pm S D$ (range).

NCS, nerve conduction study; BCTSQ, Boston Carpal Tunnel Syndrome Questionnaire.

${ }^{a}$ Wilcoxon signed-rank test: $\mathrm{P}<0.05$; ${ }^{\text {b }}$ The distribution of the $\mathrm{BCTSQ}$ score preoperatively (Mann-Whitney U test P-value $=0.335$ ) and at 1 -year post-intervention (MannWhitney $\mathrm{U}$ test $\mathrm{P}$-value $=0.801$ ) did not differ significantly across patients with complaints existing for more or less than 1 year; ${ }^{c}$ The distribution of the $\mathrm{BCTSQ}$ score preoperatively (Mann-Whitney U test P-value $=0.291$ ) and at 1-year post-intervention (Mann- Whitney U test P-value $=0.801$ ) did not differ significantly across patients with moderate versus severe NCS abnormalities.

Table 11. Patient satisfaction at 3 months and 1-year post-intervention

\begin{tabular}{|lcc|}
\hline Patient satisfaction & $\begin{array}{c}\text { At } 3 \text { months }(\mathrm{T} 1) \\
(\mathrm{n}=\mathbf{5 3})\end{array}$ & $\begin{array}{c}\text { At } 12 \text { months (T2) } \\
(\mathrm{n}=51)\end{array}$ \\
\hline VAS $^{\text {a) }}$ & $78.4 \pm 23.4(6-100)$ & $80.9 \pm 26.0(0-100)$ \\
\hline
\end{tabular}

Values are presented as mean $\pm \mathrm{SD}$ (range).

${ }^{\text {a) }}$ VAS, visual analogue scale (in the range of 0 to $100,0=$ dissatisfied to $100=$ completely satisfied).

and follow-up of patients who provided inconsistent answers. The use of only questionnaires only has been shown to be inferior to verbal consultations due to the risk of misinterpretation and misunderstanding; follow-up by telephone compensated for this shortcoming. An additional strength of this study is that each patient received the same intervention (mini-open CTR) performed by the same surgeon, which further limited confounding factors. Previous descriptions of the advantages of the mini-open approach have been published $[8,9]$, but they either had a shorter follow-up or a smaller sample than this study. In our study, $11 \%$ of patients suffered from an early complication (within 3 months post-intervention) (Table 6), which is in accordance with the published rates in the literature, which range from $1 \%$ to $25 \%$ [10]. No patients suffered from more than one complication. The re-exploration rate was $3.8 \%(n=2)$ and no patients suffered other major complications. This is currently the only study with this length of follow-up after a mini-open CTR. Comparisons of our outcomes with those of other studies are therefore not possible. A remarkable finding was the temporary increase in mild paraesthesia at 3 months post-intervention. Although it is known that the median nerve cross-sectional area (swelling) decreases over time following CTR, this may not necessarily correlate with the improvement of symptoms [11], and it is also possible that strain of the median nerve [12] may not have increased rapidly enough in this group of patients. Our study did not show a relationship between the duration of symptoms or the extent of NCS abnormalities preoperatively and the degree of postoperative recovery. This is in agreement with a large retrospective study by Choi and Ahn [13], which reported no association between postoperative outcomes and the severity of electromyography findings or duration of symptoms. In contrast to a previous study [14] that suggested that age was mildly predictive of post-release distal motor latency changes, this study found no correlation between the persistence of early (within 3 months post-intervention) paraesthesia and patients' age (Table 8 ).

The 22.9-point difference between the preoperative and postoperative BCTSQ scores significantly exceeded the clinically relevant difference of 1.7 points (Table 9) [15,16]. The VAS score also showed clinically relevant improvements for pain during activity and at rest (33.3 and 31 points respectively) (Table 9), which may suggest that using only the BCTSQ for CTR outcome studies may be sufficient in the future [17].

Our study showed a discrepancy between the clinical and patient-reported outcomes and patient satisfaction. Symptom relief was less or occurred after a longer period of time than patients expected, resulting in early patient disappointment, despite clear improvements in clinical outcomes. Preoperative expectations have previously been shown to influence postoperative satisfaction [18]. The findings of our study suggest that there seems to be room for more thorough preoperative counselling on the expected time of recovery.

This study has some limitations that should be noted, such as its limited power (a patient cohort of 72 patients) and the lack of a case-control design. Another limitation is the disappointing proportion of incomplete datasets (with variation between subjective and objective measurements), which ranged from $26 \%$ 
to $31 \%$, depending on which parameter was assessed, at 1 year following surgery. Data from the cohort that completed the study may thus not necessarily be absolutely representative of the group as a whole. Nevertheless, the demographic and clinical characteristics, NCS abnormalities, and duration of symptoms were similar in the study group and the group that was lost to follow-up. The reasons for stopping participation were unknown in most cases, but a possible explanation is that patients were reluctant to bear the costs of travelling and absence from work without financial compensation.

The outcomes of this study reflect the effectiveness of our current approach. The cost advantage, and thus the efficiency of the mini-open approach CTR has also been underscored by a very recent study by Zhang et al. [19]. Finally, several additional conclusions can be drawn from our study. First, a longer duration of symptoms (more than 1 year) and severity of abnormalities on NCS did not influence the postoperative outcomes, suggesting that preoperative NCSs are of no prognostic value and that a long duration of median nerve compression does not necessarily lead to irreversible nerve damage. Secondly, we found that the recovery period was longer than expected, especially regarding paraesthesia. The guidelines of the Netherlands Society of Neurology suggest that a period of 3 to 6 months post-intervention is normal for the persistence of complaints (loss of strength and coordination, pillar pain, scar pain, desensitization [also at the long term], mild paraesthesia) [2], which may in fact be too short. If similar results are obtained in the future, it might be useful to adapt the information obtained from patients preoperatively. Our study showed that some patients likely had did unrealistic preoperative expectations. Clearer or more specific preoperative counselling is therefore necessary. A well-informed patient and a well-performed mini-open CTR are the prerequisites for a good outcome.

\section{NOTES}

\section{Conflict of interest}

No potential conflict of interest relevant to this article was reported.

\section{Ethical approval}

The study was approved by the Institutional Review Board of Gelre Hospital (IRB No. RF TCO nr.16.29) and performed in accordance with the principles of the Declaration of Helsinki. Written informed consents were obtained.

\section{Patient consent}

The patients provided written informed consent for the publica- tion and the use of their images.

\section{Author contribution}

Conceptualization and project administration: Theuvenet WT, van den Broeke LR. Data curation: van den Broeke LR. Formal analysis: van den Broeke LR. Funding acquisition: Theuvenet WJ, van Wingerden JJ. Methodology: all authors. Visualization: van den Broeke LR. Writing original draft: all authors. Writing review \& editing: van Wingerden JJ, van den Broeke LR.

\section{ORCID}

Lieselotte R. van den Broeke https://orcid.org/0000-00018520-7630

Willem. J. Theuvenet https://orcid.org/0000-0002-25600315

Jan. J.van Wingerden https://orcid.org/0000-0001-76222660

\section{REFERENCES}

1. Padua L, Coraci D, Erra C, et al. Carpal tunnel syndrome: clinical features, diagnosis, and management. Lancet Neurol 2016;15:1273-84.

2. Nederlandse Vereniging voor Neurologie. Richtlijn 'Diagnostiek en behandeling van het carpale-tunnelsyndroom [Internet]. 2005, 1-149. Available from https://www.neurologie.nl/publiek/beroepsinformatie/richtlijnen/nvn-richtlijnen.

3. Iida J, Hirabayashi H, Nakase H, et al. Carpal tunnel syndrome: electrophysiological grading and surgical results by minimum incision open carpal tunnel release. Neurol Med Chir (Tokyo) 2008;48:554-9.

4. Graham B, Peljovich AE, Afra R, et al. The American academy of orthopaedic surgeons evidence-based clinical practice guideline on: management of carpal tunnel syndrome. J Bone Joint Surg Am 2016;98:1750-4.

5. Vasiliadis HS, Georgoulas P, Shrier I, et al. Endoscopic release for carpal tunnel syndrome. Cochrane Database Syst Rev 2014;(1):CD008265.

6. Sayegh ET, Strauch RJ. Open versus endoscopic carpal tunnel release: a meta-analysis of randomized controlled trials. Clin Orthop Relat Res 2015;473:1120-32.

7. Smits FV, Ottenhof M, Feitz R, et al. Nederlandse vertaling van de 'Boston carpal Tunnel Questionnaire'voor evaluatie van het carpaletunnel-syndroom (BcTQ-dIV). Nederlands Tijdschrift voor Plastische Chirurgie 2014;5:70-3.

8. Anbarasan A, Thevarajah N, Sadagatullah AN. The functional outcome of mini carpal tunnel release. J Hand Micro- 
surg 2017;9:6-10.

9. Murthy PG, Goljan P, Mendez G, et al. Mini-open versus extended open release for severe carpal tunnel syndrome. Hand (NY) 2015;10:34-9.

10. Soltani AM, Allan BJ, Best MJ, et al. Revision decompression and collagen nerve wrap for recurrent and persistent compression neuropathies of the upper extremity. Ann Plast Surg 2014;72:572-8.

11. Kim JK, Koh YD, Kim JO, et al. Changes in clinical symptoms, functions, and the median nerve cross-sectional area at the carpal tunnel inlet after open carpal tunnel release. Clin Orthop Surg 2016;8:298-302.

12. Yoshii $Y$, Tung WL, Ishii T. Measurement of median nerve strain and applied pressure for the diagnosis of carpal tunnel syndrome. Ultrasound Med Biol 2017;43:1205-9.

13. Choi SJ, Ahn DS. Correlation of clinical history and electrodiagnostic abnormalities with outcome after surgery for carpal tunnel syndrome. Plast Reconstr Surg 1998;102:237480.
14. Rotman MB, Enkvetchakul BV, Megerian JT, et al. Time course and predictors of median nerve conduction after carpal tunnel release. J Hand Surg Am 2004;29:367-72.

15. Kim JK, Yi JW, Kook SH. The minimal clinical important difference of the carpal tunnel syndrome questionnaire in surgically treated patients. J Hand Surg Am 2011;36:7.

16. Rodrigues JN, Mabvuure NT, Nikkhah D, et al. Minimal important changes and differences in elective hand surgery. J Hand Surg Eur Vol 2015;40:900-12.

17. Heller GZ, Manuguerra M, Chow R. How to analyze the visual analogue scale: myths, truths and clinical relevance. Scand J Pain 2016;13:67-75.

18. Mahomed NN, Liang MH, Cook EF, et al. The importance of patient expectations in predicting functional outcomes after total joint arthroplasty. J Rheumatol 2002;29:1273-9.

19. Zhang S, Vora M, Harris AH, et al. Cost-minimization analysis of open and endoscopic carpal tunnel release. J Bone Joint Surg Am 2016;98:1970-7. 